\title{
Insulation and Body Temperature of Prepubescent Children Wearing a Thermal Swimsuit During Moderate-Intensity Water Exercise
}

\author{
Hitoshi Wakabayashi, Koichi Kaneda, Masashi Okura and Takeo Nomura \\ Institute of Comprehensive Human Sciences, University of Tsukuba
}

\begin{abstract}
This study investigated thermal swimsuits (TSS) effects on body temperature and thermal insulation of prepubescent children during moderate-intensity water exercise. Nine prepubescent children $(11.0 \pm 0.7 \mathrm{yrs})$ were immersed in water $\left(23^{\circ} \mathrm{C}\right)$ and pedalled on an underwater cycle-ergometer for $30 \mathrm{~min}$ with TSS or normal swimsuits (NSS). The rectal temperature $\left(T_{\text {re }}\right)$ was maintained slightly higher with TSS than with NSS. The total insulation $\left(I_{\text {total }}\right)$ was significantly higher with TSS. The $\Delta T_{\text {re }}, \Delta$ mean body temperature $\left(\bar{T}_{b}\right)$, and tissue insulation $\left(I_{\text {tissue }}\right)$ in the NSS condition were correlated with $\%$ body fat, which indicated that the insulation layer of subjects with low body fat was thinner than that of obese subjects, and tended to decrease body temperature. Wearing TSS increased $I_{\text {total }}$, thereby reducing heat loss from subjects' skin to the water. Consequently, subjects with TSS were able to maintain higher body temperatures. In addition, TSS is especially advantageous for subjects with low body fat to compensate for the smaller $I_{\text {tissue }}$ J Physiol Anthropol 26(2): 179-183, 2007 http:// www.jstage.jst.go.jp/browse/jpa2
\end{abstract}

[DOI: $10.2114 /$ jpa2.26.179]

Keywords: prepubescent children, thermal insulation, body temperature, thermal swimsuit, water exercise

\section{Introduction}

The thermal conductance of water is approximately 25 times greater than that of air. During cold water immersion, body heat is rapidly conducted away from human skin to the water. Several studies have reported that moderate exercise facilitates overall heat loss during cold water immersion (McArdle et al., 1992; Keatinge and Evanse, 1961; Sloan and Keatinge, 1973) because the increased blood circulation to muscle tissues raises the conductive heat transfer from the body core to the skin, thereby reducing tissue insulation (Veicsteinas et al., 1982). Furthermore, in moderate exercise conditions, body movements through the water accelerate convective heat loss from the skin surface to the water. Children are especially likely to be affected by a cold water environment, because they have a larger surface area/mass ratio (Inoue et al., 1996; Sloan and Keatinge, 1973) and thinner subcutaneous fat layer in the trunk region compared to adults (Martin and Ward, 1996).

In the elementary schools of Japan, the recommended water temperature $\left(T_{\mathrm{w}}\right)$ during swimming class is set approximately above $23^{\circ} \mathrm{C}$. However, there has been no evaluation of the lowest $T_{\mathrm{w}}$ during swimming class based on experimental data. A $T_{\mathrm{w}}$ of $23^{\circ} \mathrm{C}$ appears not to be sufficient to maintain children's core body temperature, because of their physical characteristics as described above and the moderate exercise intensity during swimming class. Therefore, it is necessary to develop some way to maintain the core body temperature. Wearing an additional insulation layer on the skin surface is beneficial to reduce convective heat loss. Thermal swimsuits (TSS), which are partial-coverage wetsuits, were developed to use in a cool water environment for improving physical fitness or learning swimming techniques. The effects of wearing TSS have been evaluated with male adults during water immersion at rest and during low- to moderate-intensity water exercise (Wakabayashi et al., 2006b; Wakabayashi et al., 2006a). They reported that TSS could increase total insulation and maintain body temperatures, and suggested that subjects with lower body fat might receive more benefit from TSS. However, it is not clear whether prepubescent subjects can benefit from the thermal effects of wearing TSS in the same way as the adult subjects. Further evaluation of TSS with prepubescent subjects is required before introducing the TSS into elementary school swimming classes. This study investigated TSS effects on body temperature and the thermal insulation of prepubescent children during moderate-intensity water exercise at a $T_{\mathrm{w}}$ of $23^{\circ} \mathrm{C}$.

\section{Methods}

Nine male prepubescent subjects (age: $11.0 \pm 0.7 \mathrm{yrs}$, height: $144.8 \pm 6.4 \mathrm{~cm}$, weight: $37.2 \pm 5.5 \mathrm{~kg}, \%$ fat: $15.1 \pm 4.9 \%$, surface area: $1.23 \pm 0.11 \mathrm{~m}^{2}$ ) volunteered for this study. Both 
the subjects and their parents gave written informed consent. The Human Subjects Committee of the University of Tsukuba approved this study design. Their body-fat percentages ( $\%$ fat) were measured using bioelectrical impedance analysis (BC118; Tanita, Japan). The body surface area (SA) was estimated by the DuBois equation $\left(S A=0.007184 \cdot B W^{0.425} \cdot H^{0.725}\right)$, where $B W$ is the body weight and $H$ represents height.

After subjects sat in room air $\left(23-24^{\circ} \mathrm{C}\right)$ for $5 \mathrm{~min}$, they were immersed in water $\left(23^{\circ} \mathrm{C}\right)$ up to their chest on an underwater cycle-ergometer for $5 \mathrm{~min}$. They then pedalled at $50 \mathrm{rpm}$ for $30 \mathrm{~min}$. Each subject carried out the protocol twice with a normal swimsuit (NSS) and with a TSS (JCW-24100; Zipathong Co. Ltd., Japan) at submaximal exercise intensity based on pre-test HR data measured in the elementary swimming classes $\quad\left(\mathrm{HR}=130-140 \mathrm{bpm}, \quad \dot{V}_{\mathrm{O}_{2}}=25-28\right.$ $\left.\mathrm{ml} \cdot \mathrm{min}^{-1} \cdot \mathrm{kg}^{-1}\right)$. The TSS used in this study was made of nylon-faced neoprene $(1.5 \mathrm{~mm}$ thick), covering the thighs, trunk, upper arms, and neck.

During experiments, rectal temperature $\left(T_{\text {re }}\right)$ and 6 skin temperature regions were measured using thermistor sensors. The mean skin temperature $\left(\bar{T}_{s k}\right)$ and mean body temperature $\left(\bar{T}_{b}\right)$ were calculated using the following equations.

$$
\begin{aligned}
\bar{T}_{s k}= & 0.07 T_{\text {head }}+0.35 T_{\text {chest }}+0.07 T_{\text {upperarm }}+0.12 T_{\text {forearm }} \\
& +0.19 T_{\text {thigh }}+0.20 T_{\text {calf }} \\
\bar{T}_{b}= & 0.67 T_{\text {re }}+0.33 \bar{T}_{\text {sk }}
\end{aligned}
$$

Expired gases were continuously assessed using a mass spectrometer (WEMS2000; Westron Corp., Japan). Values of the minute ventilation $\left(\dot{V}_{\mathrm{E}}\right)$, oxygen uptake $\left(\dot{V}_{\mathrm{O}_{2}}\right)$, carbon dioxide elimination $\left(\dot{V}_{\mathrm{CO}_{2}}\right)$, and respiratory exchange ratio $(R E R)$ were averaged every $1 \mathrm{~min}$.

Total metabolic heat production $(M)$ was calculated from $\dot{V}_{\mathrm{O}_{2}}$ and RER. Metabolic heat production from the unit skin surface $\left(M_{\mathrm{s}}\right)$ was calculated using the following formula:

$$
M_{\mathrm{s}}=0.92 \cdot M / S A \quad\left[\mathrm{~W} \cdot \mathrm{m}^{-2}\right],
$$

where the respiratory heat loss was assumed to be $8 \%$ of $M$.

Body heat storage $\left(S_{\mathrm{s}}\right)$ was calculated from $\Delta \bar{T}_{b}, B W$, and the human body specific heat capacity $\left(C_{\mathrm{b}}\right)$ using the following formula.

$$
S_{\mathrm{s}}=C_{\mathrm{b}} \cdot \Delta \bar{T}_{b} \cdot B W / S A \quad\left[\mathrm{~W} \cdot \mathrm{m}^{-2}\right]
$$

Heat loss from the skin to the water $\left(H_{\mathrm{s}}\right)$ was calculated as

$$
H_{\mathrm{s}}=M_{\mathrm{s}}-S_{\mathrm{s}} \quad\left[\mathrm{W} \cdot \mathrm{m}^{-2}\right] .
$$

Total insulation $\left(I_{\text {total }}\right)$ and tissue insulation $\left(I_{\text {tissue }}\right)$ were calculated using the following formulae, according to Rennie et al. (1962).

$$
\begin{aligned}
& I_{\text {total }}=\left(\begin{array}{ll}
\left.T_{\mathrm{re}}-T_{\mathrm{w}}\right) / H_{\mathrm{s}} & {\left[{ }^{\circ} \mathrm{C} \cdot \mathrm{m}^{2} \cdot \mathrm{W}^{-1}\right]} \\
I_{\text {tissue }}=\left(T_{\mathrm{re}}-\bar{T}_{s k}\right) / H_{\mathrm{s}} & {\left[{ }^{\circ} \mathrm{C} \cdot \mathrm{m}^{2} \cdot \mathrm{W}^{-1}\right]}
\end{array}\right.
\end{aligned}
$$

Suit insulation $\left(I_{\text {suit }}\right)$ was calculated using the following formulae, according to Shiraki et al. (1986).

$$
I_{\text {suit }}=I_{\text {total }}-I_{\text {tissue }} \quad\left[{ }^{\circ} \mathrm{C} \cdot \mathrm{m}^{2} \cdot \mathrm{W}^{-1}\right]
$$

Comparisons of body temperature datasets were performed using two-way analysis of variance and further tested using a paired t-test at various time points between experimental conditions. All other data were compared using paired t-tests between experimental conditions. Pearson's product moment correlation coefficients were used to determine the degree of association between subjects' \%fat and $\Delta T_{\text {re }}, \Delta \bar{T}_{b}, I_{\text {tissue }}$. Statistical significances $(p<0.05)$ between TSS and NSS are shown with an asterisk $(*)$ in the Figures and Tables.

\section{Results}

Average values of $\dot{V}_{\mathrm{O}}, \dot{V}_{\mathrm{E}}, \mathrm{HR}$, and RPE during water exercise are shown in Table 1. Values of $\dot{V}_{\mathrm{O}_{2}}, \mathrm{HR}$, and RPE showed no differences between TSS and NSS conditions. The $\dot{V}_{\mathrm{E}}$ was significantly lower with TSS than with NSS $(p<0.05)$.

Changes in $T_{\text {re }}$ and $\bar{T}_{s k}$ are shown in Fig. 1. At the beginning of water immersion, $\bar{T}_{s k}$ dropped rapidly with NSS; however, a

Table 1 Cardiovascular responses during exercise in $23^{\circ} \mathrm{C}$ water

\begin{tabular}{lrc}
\hline \multicolumn{1}{c}{ Swimsuit } & NSS & TSS \\
& mean SE & mean SE \\
\hline$\dot{V}_{\mathrm{O}_{2}\left(\mathrm{ml} \cdot \mathrm{min}^{-1} \cdot \mathrm{kg}^{-1}\right)}$ & $27.6(1.7)$ & $25.5(1.5)$ \\
$\dot{V}_{\mathrm{E}}\left(1 \cdot \mathrm{min}^{-1}\right)$ & $32.4(1.4)$ & $28.7(1.3)^{*}$ \\
$\mathrm{HR}(\mathrm{bpm})$ & $138.1(5.2)$ & $135.4(5.0)$ \\
$\mathrm{RPE}$ & $12.0(0.7)$ & $12.1(0.5)$ \\
\hline
\end{tabular}

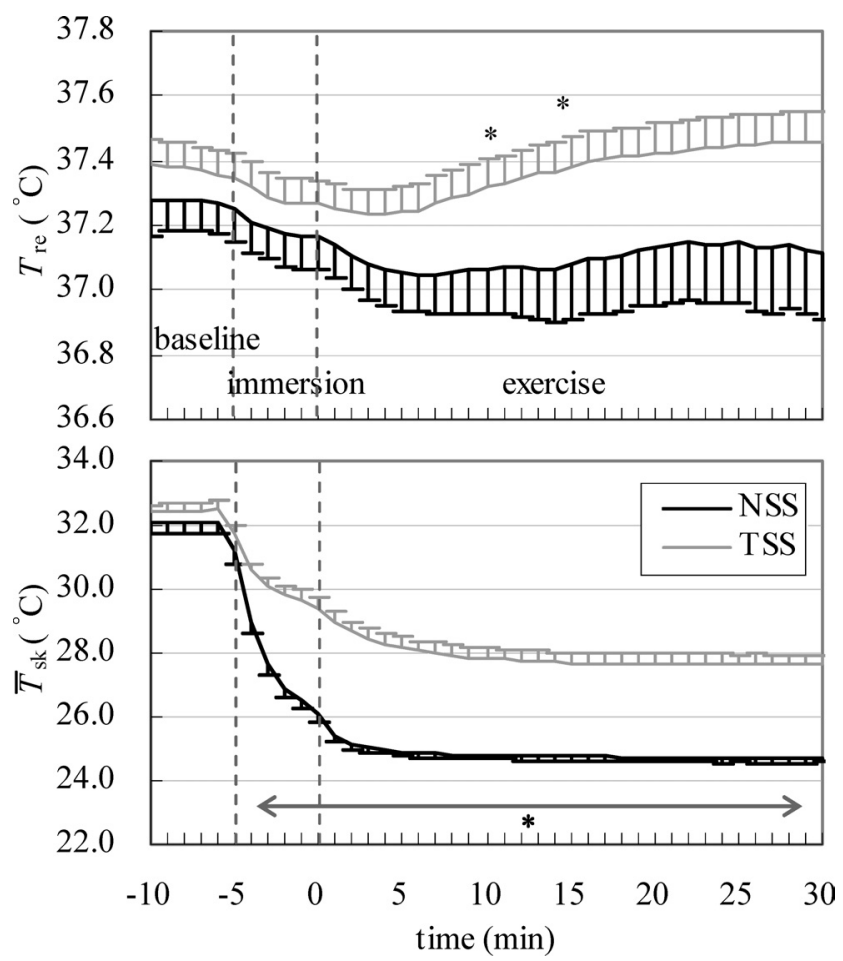

Fig. 1 Body temperature change during immersion and exercise in water $($ mean \pm SE) 


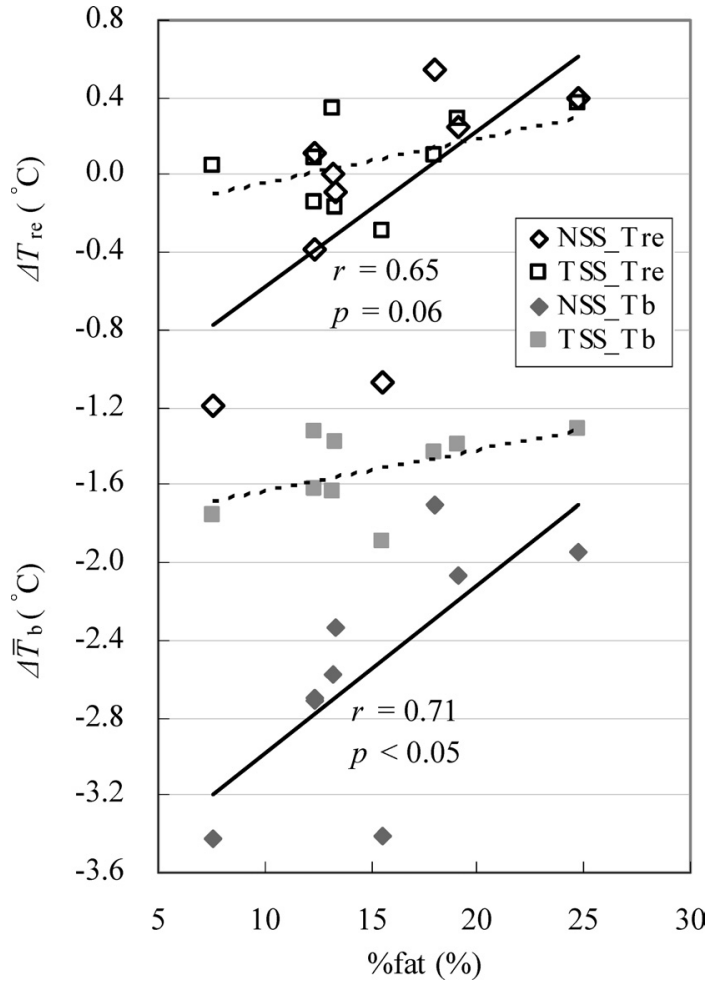

Fig. 2 The relationship between subjects' \%fat and $\Delta T_{\mathrm{re}}, \Delta \bar{T}_{\mathrm{b}}$.

slower decrease was found with TSS. After the onset of water exercise, $\bar{T}_{s k}$ decreased gradually for approximately $10 \mathrm{~min}$, then remained stable until the end of immersion in both conditions. $\bar{T}_{s k}$ was significantly higher with TSS than with NSS throughout the exercise $(p<0.05)$. During exercise, $T_{\text {re }}$ decreased slightly from the pre-immersion baseline with NSS, but increased slightly with TSS; $T_{\text {re }}$ was significantly higher with TSS than with NSS from 10 min to $15 \min (p<0.05)$.

Figure 2 shows the relationship between subjects' \%fat and $\Delta T_{\text {re }}, \Delta \bar{T}_{b}$ at the end of exercise. The $\Delta T_{\text {re }}$ and $\Delta \bar{T}_{b}$ of each subject in the NSS condition were positively correlated with their \%fat ( $r=0.65, p=0.06 ; r=0.71, p<0.05$ ). However, in the TSS condition subjects maintained their $T_{\text {re }}$, and no correlation was observed between subjects' \%fat and the $\Delta T_{\text {re }}$ and $\Delta \bar{T}_{b}$ of each subject.

The $M_{\mathrm{s}}, S_{\mathrm{s}}$, and $H_{\mathrm{s}}$ during the $30 \mathrm{~min}$ water exercise are shown in Fig. 3. The $M_{\mathrm{s}}$ showed no differences between the TSS and NSS conditions. The $S_{\mathrm{s}}$ were significantly lower in TSS than in NSS $(p<0.05)$. TSS showed significantly lower $H_{\mathrm{s}}$ than in the NSS condition $(p<0.05)$.

The results of $I_{\text {total }}, I_{\text {tissue }}$ and $I_{\text {suit }}$ during the water exercise are shown in Fig. 4. The $I_{\text {total }}$ was significantly higher in the TSS than in the NSS condition $(p<0.05)$. The $I_{\text {tissue }}$ showed no differences between the TSS and NSS conditions.

Figure 5 shows the relationship between subjects' \%fat and the $I_{\text {tissue }}$ in the NSS condition. The $I_{\text {tissue }}$ in the NSS condition correlated significantly with subjects' \%fat $(r=0.79, p<0.05)$.

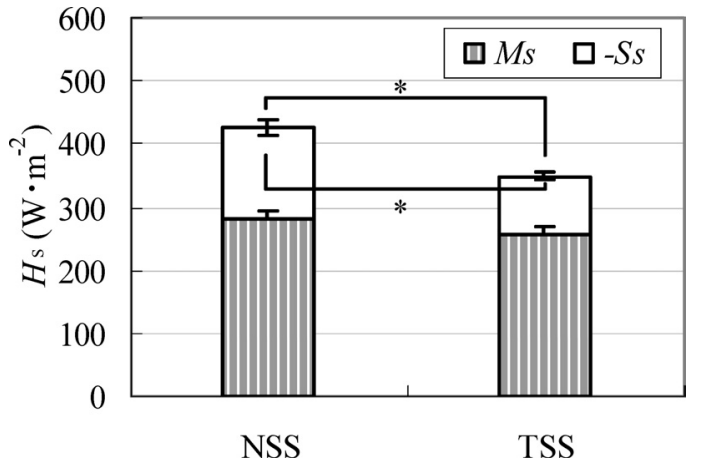

Fig. 3 Metabolic heat production, heat storage, and heat loss from the skin surface during $30 \mathrm{~min}$ water exercise (mean $\pm \mathrm{SE}$ ).

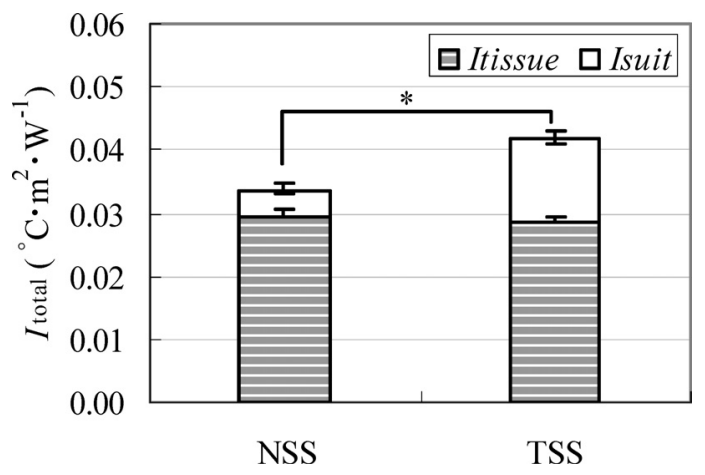

Fig. 4 Insulation of tissue, suit, and total insulation during $30 \mathrm{~min}$ water exercise (mean $\pm \mathrm{SE})$.

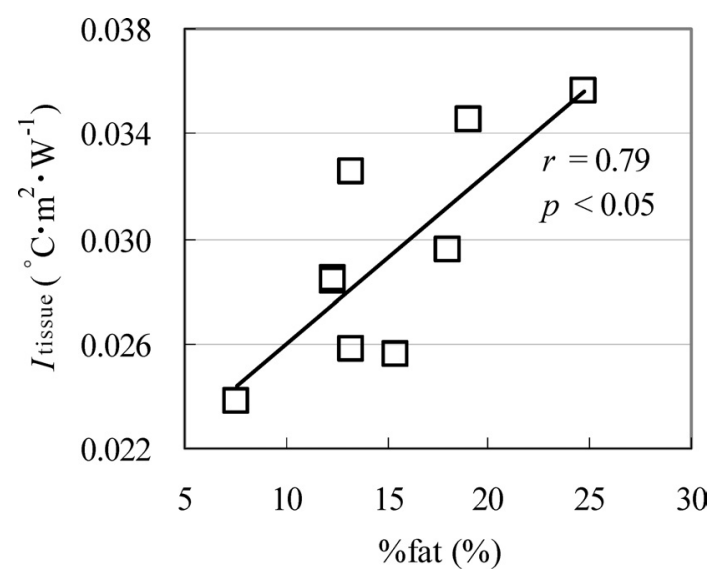

Fig 5 The relationship between subjects' \%fat and $I_{\text {tissue }}$ during water exercise with NSS.

\section{Discussion}

\section{Body temperature}

At the beginning of water immersion, $\bar{T}_{s k}$ decreased rapidly in the NSS condition. On the other hand, the TSS condition showed a slower decrement of $\bar{T}_{s k}$ (Fig. 1). Kang et al. (1983) and Shiraki et al. (1986) reported a slower and smaller decrement of $\bar{T}_{s k}$ in wetsuit-protected divers compared with the 
naked condition, similar to the findings of the present study. Since the TSS used in the present study was made of neoprene, similar to the wetsuits, the TSS was able to reduce water inflow to the clothed body parts and attenuate the convective and conductive heat loss, thus maintaining a higher $\bar{T}_{s k}$.

From the present results, wearing TSS enabled subjects to maintain a higher $T_{\text {re }}$ than with NSS. However, the decrement of $T_{\text {re }}$ during water exercise with NSS was small, and above $37^{\circ} \mathrm{C}$. It seemed to be sufficient to allow the swimming class to proceed without TSS. However, there were large individual differences in body temperature change during water exercise; in particular, subjects with the lowest $\%$ fat decreased $T_{\text {re }}$ more than $1{ }^{\circ} \mathrm{C}$. A positive correlation was observed between subjects' $\%$ fat and the $\Delta T_{\text {re }}$ and $\Delta \bar{T}_{b}$ of each subject in the NSS condition. Sloan and Keatinge (1973) investigated the oral temperature $\left(T_{\text {oral }}\right)$ of boys and girls aged 8-20 years during $40 \mathrm{~min}$ submaximal swimming in water at $20.3^{\circ} \mathrm{C}$, and reported a significant correlation between individual's skinfold thickness and the rate of $T_{\text {oral }}$ fall similar to the present result. Holmer and Bergh (1974) investigated the esophagus temperature $\left(T_{\mathrm{es}}\right)$ changes of male adults during $20 \mathrm{~min}$ submaximal swimming in water at 18,26 and $34^{\circ} \mathrm{C}$. They reported that large individual differences and a significant correlation between a subject's mean skinfold thickness and $\Delta T_{\text {es }}$ were observed at $18^{\circ} \mathrm{C}$. The individual differences became smaller at $26^{\circ} \mathrm{C}$, and, finally, no individual differences or correlations were observed at $34^{\circ} \mathrm{C}$. A similar thermal effect reducing individual differences was observed in the present study by wearing TSS.

\section{Thermal insulation}

The additional insulation layer of the TSS increased $I_{\text {total }}$ in the TSS condition. The increment of $I_{\text {total }}$ might have engendered the lower $H_{\mathrm{s}}$ during water exercise in the TSS condition compared with that in the NSS condition. Consequently, subjects with TSS were able to maintain higher body temperatures than those same subjects with NSS. The $I_{\text {tissue }}$ showed no differences between the TSS and NSS conditions, which suggested that the peripheral blood flow during water exercise was similar in both conditions. Similar results were observed in the previous study evaluating the effect of TSS during water exercise with male adult subjects (Wakabayashi et al., 2006a). They suggested that wearing TSS has no effect on the peripheral blood flow, based on the results of similar $I_{\text {tissue }}$ and cardiovascular responses between suit conditions.

The significant correlation between \%fat and $I_{\text {tissue }}$ in the NSS condition indicated that the insulation layer of subjects with low body fat was thinner than that of obese subjects (Hayward and Keatinge, 1981). Wakabayashi et al. (2006a) reported a correlation between the male adult subjects' skinfold thickness and their $I_{\text {tissue }}$ during moderate-intensity water exercise with NSS, similar to the findings of the present study. The present result suggests that wearing TSS is advantageous for prepubescent subjects with low body fat to compensate for the smaller $I_{\text {tissue }}$ None of the previous wetsuit studies have assessed suit-attributable differences among subjects' physical characteristics using the $I_{\text {tissue }}$ parameter. We can suggest the greater usefulness of wearing TSS for subjects with low body fat by indicating the positive correlation between \%fat and $I_{\text {tissue }}$.

\section{Conclusion}

During exercise in $23^{\circ} \mathrm{C}$ water, wearing TSS served to increase $I_{\text {total }}$ by adding $I_{\text {suit }}$, thereby reducing heat loss from prepubescent subjects' skin to the water. Consequently, subjects with TSS were able to maintain higher body temperatures than those same subjects with NSS. In addition, it was suggested that TSS was especially advantageous for subjects with low body fat to compensate for the smaller $I_{\text {tissue }}$. The prepubescent subjects with low body fat can maintain their core body temperature at the same level as the obese subjects by wearing TSS.

\section{References}

Hayward MG, Keatinge WR (1981) Roles of subcutaneous fat and thermoregulatory reflexes in determining ability to stabilize body temperature in water. J Physiol 320: 229-251

Inoue Y, Araki T, Tsujita J (1996) Thermoregulatory responses of prepubertal boys and young men in changing temperature linearly from 28 to 15 degrees C. Eur J Appl Physiol 72(3): 204-208

Kang DH, Park YS, Park YD, Lee IS, Yeon DS, Lee SH, Hong SY, Rennie DW, Hong SK (1983) Energetics of wet-suit diving in Korean women breath-hold divers. J Appl Physiol 54(6): 1702-1707

Keatinge WR, Evanse M (1961) The respiratory and cardiovascular response to immersion in cold and warm water. Q J Exp Physiol Cogn Med Sci 46: 83-94

Martin AD, Ward R (1996) Body composition. In Docherty D ed. Measurement in pediatric exercise science. Human Kinetics, British Columbia, Canada, 87-128

McArdle WD, Toner MM, Magel JR, Spina RJ, Pandolf KB (1992) Thermal responses of men and women during coldwater immersion: influence of exercise intensity. Eur J Appl Physiol 65(3): 265-270

Rennie DW, Covino BG, Howell BJ, Song SH, Kang BS, Hong SK (1962) Physical insulation of Korean diving women. J Appl Physiol 17(6): 961-966

Shiraki K, Sagawa S, Konda N, Park YS, Komatsu T, Hong SK (1986) Energetics of wet-suit diving in Japanese male breath-hold divers. J Appl Physiol 61(4): 1475-1480

Sloan REG, Keatinge WR (1973) Cooling rates of young people swimming in cold water. J Appl Physiol 35(3): 371-375

Veicsteinas A, Ferretti G, Rennie DW (1982) Superficial shell insulation in resting and exercising men in cold water. J Appl Physiol 52(6): 1557-1564 
Wakabayashi H, Kaneda K, Hanai A, Yokoyama S, Nomura T (2006a) Insulation and body temperature changes by wearing a thermal swimsuit during low to moderate intensity water exercise. In Vilas-Boas JP, Alves F, Marques A eds. Biomechanics and Medicine in Swimming X. Portuguese Journal of Sport Sciences, 6 (supl. 2): 179-182

Wakabayashi H, Hanai A, Yokoyama S, Nomura T (2006b) Thermal insulation and body temperature wearing a thermal swimsuit during water immersion, J Physiol Anthropol 25(5): $331-338$

This article was presented at the 8th International Congress of
Physiological Anthropology, 2006 (ICPA 2006), in Kamakura, Japan

Received: September 28, 2006

Accepted: November 28, 2006

Correspondence to: Hitoshi Wakabayashi, Institute of Comprehensive Human Sciences, University of Tsukuba, 1-1-1, Tennoudai, Tsukuba, Ibaraki, Japan

Phone: +81-29-853-6338

Fax: +81-29-853-6338

e-mail: waka_swim@hotmail.com 